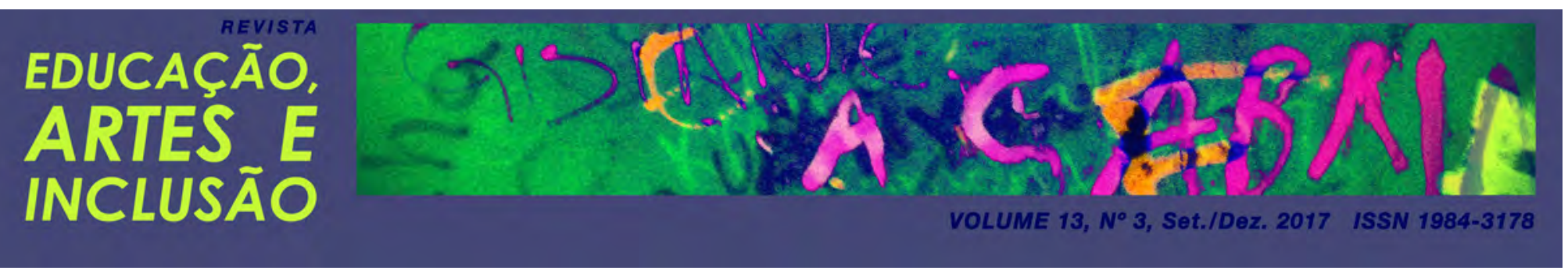

\title{
ARTE E DOCÊNCIA: NOTAS SOBRE O PROJETO TRANSVISÕES
}

\author{
ART AND TEACHING: NOTES ABOUT THE TRANSVISION \\ PROJECT
}

DOI: http://dx.doi.org/10.5965/1984317813032017052

Suzana Feldens Schwertner, Natália Schuck, Alissara Zanotelli, Morgana Domênica Hattge - Universidade do Vale do Taquari

\begin{abstract}
RESUMO
O texto apresenta o relato de um projeto intitulado Transvisões: aquarela, nanquim e pintura tridimensional, realizado a partir dos estudos de um grupo de pesquisa de uma Universidade no interior do Rio Grande do Sul. O objetivo deste relato é apresentar as vivências dos envolvidos no projeto, bem como visibilizar a partir de quem/do que ele é pensado e seus efeitos na docência das participantes. Tal projeto teve como ações oficinas relacionadas à arte, ministradas por artistas locais, tendo como público-alvo professoras da educação básica. No trabalho com os artistas foram desenvolvidas atividades relacionadas às suas produções bem como discussões com relação à criação das obras. Após a atividade foram realizadas entrevistas com oito professoras participantes. Na análise das entrevistas foi possível perceber que a participação das professoras nas oficinas as fez pensar sobre as aprendizagens, tanto de seus alunos quanto as suas. Além disso, percebeu-se a desconstrução das dicotomias belo e feio, bom e mau, certo e errado, no que diz respeito à arte e docência. Ainda, após a participação nas oficinas, as docentes manifestaram o desejo da construção de outras propostas que sigam buscando articulações entre arte e docência.
\end{abstract}

Palavras-chave: Docência. Arte. Formação. Educação Básica.

\begin{abstract}
This text describes the work of a project named Transvisions: watercolor, nankeen and threedimensional paintings, developed from the experiences and researches of a research group from an university in Rio Grande do Sul. The purpose is to present experiences of the Project, and to highlight from who/what it is planned and its effects on the teaching process of the participants. It had as actions workshops about arts, conducted by local artist, and as target audience teachers of the elementary education. In the exercise with the artist were developed activities related to their artistic productions, and discussions about conceptions of the artworks. After, interviews were performed with the eight participant teachers. In the analysis of the interview was noticed that their participation in the workshops made the teachers think about the learnings of their students and their own learnings. Besides, we noticed the deconstruction of the dichotomy beautiful and ugly, good and bad, right and wrong concerned to art and teaching. Furthermore, after the participation, the teachers expressed the desire of the development of more initiatives that keep promoting articulations between art and teaching.
\end{abstract}

Keywords: Teaching. Art. Development. Elementary Education. 


\section{COMO COMEÇOU}

O conhecimento sobre arte não termina no conhecimento da obra de arte, ele é uma ferramenta para compreender o mundo (HELGUERA, 2011, p. 12).

Comecemos pelo nome do projeto que norteia a escrita do presente trabalho: Transvisões. Na língua portuguesa, o prefixo "trans" remete à ideia de algo para "além de" ou "através de"; transver significa ter a visão para além de algo, com o objetivo de enxergarmos através, atravessar. É no atravessamento que entendemos a possibilidade de um currículo que se constrói para além dos muros da escola. O currículo entendido como algo que constitui o sujeito é também pensado como diferença, pois “[...] a realidade é multiplicidade, é diferença" (GALLO, 2004, p. 40).

Ou seja, mesmo que tentemos tornar o mundo gerido por apenas uma verdade, tentando fazer dele um universo homogêneo de viver, ela escapa e é diferença. Nesse sentido, o "trans" apresentado por este texto se encontra na transversalidade, podendo esta ser pensada como "[...] o tipo de trânsito por entre os liames de um rizoma de um emaranhado de saberes" (GALLO, 2004, p. 42), que se trans-veem, a fim de produzir conhecimento como uma realidade múltipla e um engendramento de saberes.

A partir dessa premissa, surge a dúvida: transver o quê? Nesse contexto, ou seja, do projeto e suas interações com a arte buscou-se, a partir de propostas artísticas e pedagógicas, proporcionar para docentes da Educação Infantil e também de Ensino Fundamental momentos para "transverem" suas práticas e seus caminhos de atuação no campo educacional por meio de experiências estéticas e artísticas. "Transverem" no sentido de proporcionar questionamentos, tensionar as práticas que vêm se realizando, a fim de pensar a arte na docência como uma possibilidade de trans-formar a vida, a docência, o ensino, a aprendizagem.

O Transvisões: aquarela, nanquim e pintura tridimensional - que será objeto deste relato - foi parte constituinte do projeto de pesquisa "O currículo em espaços escolares e não escolares no Brasil e na Colômbia: diferentes relações com o ensinar e aprender", vinculado ao Grupo de pesquisa Currículo, Espaço, Movimento (CEM) e ao Mestrado em Ensino de 
uma universidade do interior do Rio Grande do Sul. Tal projeto de pesquisa teve por objetivo investigar as especificidades curriculares em espaços escolares e não escolares e suas relações e cruzamentos com movimentos escolarizados e não escolarizados, tomando como aporte teórico Gilles Deleuze, Michel Foucault e Roland Barthes. O campo empírico do projeto de pesquisa constitui-se de três espaços escolares, incluindo escolas municipais do Vale do Taquari/RS e uma situada em Bogotá, na Colômbia, e dois não escolares, compostos pelo Museu de Arte do Rio (MAR - Rio de Janeiro) e pela Fundação Iberê Camargo (Porto Alegre/RS).

A partir das conversações decorrentes do Grupo de Pesquisa, evidenciou-se a necessidade de levar a comunidade externa, no caso, as professoras, a pensar e produzir junto. No entanto, a arte aqui é tomada como possibilidade e invenção/intervenção didática, de modo que os artistas propõem inventar junto, traçar coletivamente estratégias a fim de que os próprios partícipes criem e estabeleçam o caminho didático a seguir. Porque a rotina, o cansaço, a falta de tempo são fatores que podem auxiliar a não nos movermos, a não permitir pensar sobre o que realizamos. Assim, o Projeto vem como um potencializador da prática docente.

Ainda, historicamente, os espaços de arte, os museus, livros didáticos, costumam conduzir a prática do professor junto a seus alunos, através de materiais elaborados por curadores e coordenadores pedagógicos acerca dos modos de fruição e da construção de práticas junto aos alunos a partir da fruição de obras de arte. Geralmente, ao visitar uma exposição de arte com seus alunos, o professor já recebe um material pedagógico, com sugestões didáticas, previamente elaborado, para que possam seguir o caminho já pensado.

Essa é uma prática comum na maioria dos museus e dessa forma não costuma haver participação dos professores e alunos na criação das estratégias didáticas vivenciadas nas escolas. Professores e alunos costumam ser agentes passivos neste processo, pois já recebem os manuais estruturados a partir do desejo e da criação de outrem. No entanto, no projeto que apresentamos neste relato, a arte é pensada como possibilidade de invenção/intervenção didática, a qual os artistas podem propor, inventar junto, traçar coletivamente estratégias a fim de que os próprios partícipes criem e estabeleçam o caminho didático a seguir. 
O projeto Transvisões: aquarela, nanquim e pintura tridimensional, desenvolvido com sete escolas parceiras da pesquisa, teve como objetivo conduzir as professoras a um caminho de produção de estratégias de intervenção pedagógica com os seus alunos, por meio de sua participação em três oficinas artísticas. Dessa forma, os professores deixam de ser simplesmente receptores e reprodutores de práticas produzidas por outros atores do processo. Ministradas por artistas gaúchos nos meses de maio e junho de 2016, nos turnos da manhã e tarde, esses encontros possibilitaram às professoras participantes conhecer diferentes experimentações no campo da arte.

Trata-se, também, de aproximar o universo da escola e da universidade, por meio da divulgação de projetos de pesquisa, de projetos de extensão e de atividades como o Transvisões, articulando o compromisso social da pesquisa. Como questionam Falcão e Cerqueira: "O que se propõe, afinal discutir, abordar, quando se fala em compromisso social da pesquisa científica?" (2012, p. 26).

Por meio desta pergunta, os autores se colocam a discutir sobre os impactos e efeitos necessários das pesquisas científicas - que usualmente ocorrem em nossas universidades - na população. $\mathrm{Na}$ área da Educação, estes efeitos são de extrema importância, pois nos levam a discutir coletivamente e pensar sobre as modificações nos processos de ensino e de aprendizagem. Por meio do projeto de pesquisa, que busca articular espaços escolares e não escolares, uma série de elementos foram destacados e discutidos teoricamente. Entre eles, os movimentos escolarizados e não escolarizados que percebemos nos diferentes espaços educativos. Pois um espaço escolar não presume que seus movimentos sejam escolarizados:

[...] quando fazemos referência aos movimentos escolarizados, tomamos como objeto de análise as projeções, os programas, os planejamentos, as arquiteturas, os currículos que produzem efeitos nos sujeitos que circulam por esses espaços (HATTGE et al., 2016, p. 51).

Ou seja, até mesmo um espaço educativo que não o escolar pode produzir movimentos escolarizados. A partir destas discussões, realizadas em diferentes estudos e publicações (SCHWERTNER, LOPES e ROVEDA, 2016; MUNHOZ e HATTGE, 2016; MUNHOZ, 
COSTA e OHLWEILER 2016), o projeto Transvisões surge como possibilidade de ativar os compromissos da pesquisa com a comunidade - aqui, especialmente, a comunidade docente. Como enfatiza Cabral (2012, p. 84):

[...] o compromisso social do pesquisador é com a geração de conhecimentos que atendam às demandas sociais e valorizem a dignidade humana; que sejam produzidos respeitando-se os aspectos éticos; que garantam a ampla participação das pessoas na geração de conhecimentos [...].

Deste modo, possibilitar este espaço das oficinas ao público docente, é ao mesmo tempo, um compromisso do pesquisador, e um momento de formação ética-estética do sujeito. É este sujeito que se coloca como docente em um determinado espaço e tempo, a escola, que precisa além de fazer, vivenciar suas experimentações curriculares.

O projeto Transvisões, do ponto de vista de seus encontros, tornou-se um potencializador de pensar, experimentar, produzir, compartilhar. No entanto, alguns projetos ficam na alçada de sua execução. Passados alguns meses, perguntas nos inquietavam, como uma curiosidade para saber os efeitos dessas vivências no fazer docente destas professoras participantes das oficinas. Sendo assim, nos deslocamos até as escolas, com uma visita previamente agendada, a fim de conversar com as professoras sobre a participação nas oficinas e os efeitos em sua docência.

O escrito que segue tem o propósito de expor sobre a ideia e realização do Transvisões, seus parceiros e encontros potentes. Também poderemos acompanhar o relato das professoras participantes e o que dizem sobre sua participação, bem como efeitos na prática docente.

\section{PENSANDO O TRANSVISÕES}


O projeto teve como objetivo estimular a criação de novas propostas em todas as áreas da escola, não somente em arte. Loponte (2013) ressalta a importância de uma docência artista marcada por possibilidades de invenção contínua, buscando modos flexíveis e mais artistas para a difícil tarefa que é educar em tempos contemporâneos. Conforme Agamben (2009, p. 59):

\begin{abstract}
A contemporaneidade é uma singular relação com o próprio tempo, que adere a este, e ao mesmo tempo, dele toma distâncias; mais precisamente, essa é a relação com o tempo que a este adere através de uma dissociação e um anacronismo. Aqueles que coincidem muito plenamente a época, que a tudo coincidem muito plenamente com a época, que em todos os aspectos a esta aderem perfeitamente, não são contemporâneos porque, exatamente por isso, não conseguem vê-la, não podem manter fixo o olhar sobre ela.
\end{abstract}

Pensar a contemporaneidade é entendê-la, ainda, na sua relação com a escola, ao estabelecer um olhar que se afasta e se aproxima, a fim de poder movimentar o que precisa ser potencializado. Um modo de educar que envolve sujeitos diferentes daqueles que fomos, ou que até pouco tempo entendíamos como o sujeito da educação: aquele sujeito emancipado, que primava por uma estabilidade, que previa um "ponto de chegada" em sua formação. Os docentes artistas são sujeitos que buscam estar em constante formação de conhecimentos pertinentes à vida, mais que a qualquer regimento de normatização.

Conforme Loponte, uma docência artista perpassa esses sujeitos que estão em movimento e contínuo desenvolvimento, que se constituem em uma docência imbuída de uma atitude artista consigo mesmo e com o mundo. Para a autora:

As infinitas compreensões advindas das produções artísticas desconcertam a estabilidade do que já conhecemos e, sim, têm tudo a ver com as nossas preocupações singulares (LOPONTE, 2013, p. 41).

Uma docência artista não obedece a um manual ou leis pré-estabelecidas, mas toma princípios da arte para compor-se. A docência artista não está em apenas um sujeito, mas ela 
se encontra em muitos, e quando em um, se apresenta em diferentes composições. Ela está no modo de planejar, na maneira em que o professor olha, na maneira que ele diz o que pensa, e sobretudo no modo em que se apropria e desapropria de suas crenças como docente. Como nos lembra Corazza (2005):

Ser educador não é só acumular, guardar, conservar, usar, mas também abandonar, largar, gastar e, neste gasto, readquirir, retomar, para poder revitalizar (CORAZZA, 2005, p. 13).

Para que seja possível produzir saberes outros que nos mobilizem e potencializem, por vezes, é necessário deixar velhas crenças e antigos hábitos para trás. Desfazer-se do que já não faz sentido abre caminho para a produção de outras formas de se viver a docência.

Para pensarmos a docência artista, trazemos também Balzac (2009), que nos apresenta um modo de vida chamado de artista. No entendimento de Balzac “[...] o artista é sempre grande. Ele tem uma elegância e uma vida própria, [...] tantos quantos forem os artistas, tantas serão as vidas caracterizadas por ideias novas” (p. 32). Para ele a vida artista é tomada para si e composta pelos gostos que compõem a existência, não está separada do mundo e suas linguagens. Deste modo, podemos pensar a vida docente como uma vida artista, uma vez que uma docência artista não está em ser um pintor ou escultor, mas em tomar os traços da vida de um artista a fim de compor uma docência mais própria, autêntica. Os artistas não se incomodam com o instituído, com a verdade absoluta e acreditam na realidade como um processo em construção. É preciso querer viver uma docência artista, para que ela possa existir. Tomar a docência como artista é produzi-la nos territórios híbridos, nas diferentes linguagens que o mundo, e os sujeitos nele, podem oferecer.

Nesse sentido, um professor artista é pintor, escultor, curador, bailarino, ator, músico, trapezista, inventor, e tantas outras possibilidades de uma vida artista. Nessa docência artista ele produz espaços de experimentação, amplia territórios de atuação, porque como docente artista sua possibilidade de existência está na invenção. Com criação de outros modos de existir, de pensar a vida docente, a arte, a criação, Loponte (2017) fornece algumas pistas que 
nos abrem possibilidades de pensar em como expandir territórios e criar espaços de experimentação:

Se a formação docente for capaz de expandir-se em outras direções menos racionais e prescritivas, talvez consigamos enfrentar de modo mais afirmativo a aridez que reveste muitas das práticas escolares cotidianas, dando abertura para tornar escolas e aulas em férteis "espaços de experimentação" (LOPONTE, 2017, p. 448).

Por meio destas ideias discutidas, apresentamos a seguir o projeto Transvisões e as propostas ali desenvolvidas, com o objetivo de produzir espaços de experimentação no encontro entre arte e docência.

\section{UM POUCO DO QUE ACONTECEU}

Nesta seção apresentamos a organização das oficinas, desde sua elaboração e convite às escolas e aos docentes, até o seu desenvolvimento e envolvimento das professoras no trabalho realizado. Apresentamos também algumas fotografias produzidas pelo grupo de pesquisa durante a realização das oficinas e exposição das obras dos artistas pelo campus do centro universitário.

Durante o mês de abril de 2016, mês anterior às oficinas, realizou-se a divulgação do projeto: foram entregues fôlderes nas escolas parceiras do grupo de pesquisa, além do agendamento de reuniões com as gestoras de cada espaço visitado. Pela Internet, ocorreram algumas publicações no site do Centro Universitário Univates e também houve o envio de emails para as escolas e professoras já inscritas, com orientações sobre horários e atividades a serem realizadas nas oficinas. Desde o início, todas se mostraram interessadas e empolgadas para o início dos trabalhos.

O projeto teve abertura com a conferência da professora Luciana Grupelli Loponte (UFRGS), que compartilhou um pouco dos seus estudos sobre as articulações entre arte e educação. Na oportunidade, a professora provocou o público participante a pensar sobre a sala 
de aula como um espaço artístico e também como um lugar para propostas de diversas intervenções envolvendo pinturas de parede, performances e interação entre os alunos. Na sequência, foram realizadas as oficinas direcionadas a professores da Educação Básica (Ensino Infantil e Fundamental): participaram do projeto 14 docentes. Durante a manhã, as docentes eram imersas no mundo dos artistas, conhecendo um pouco da construção de suas obras e de suas epifanias, seu processo criativo, os materiais utilizados e ideias que os faziam elaborar suas obras. No turno da tarde, as professoras se experimentaram por meio das técnicas apresentadas pelos ministrantes e aproveitaram o espaço e os materiais para vivenciarem momentos de criação.

Durante o período do projeto, os três artistas tiveram suas obras expostas na Univates e os docentes puderam explorá-las: inicialmente, junto aos artistas e posteriormente com suas turmas da Educação Infantil e Ensino Fundamental. Dentre estas participaram três turmas, duas compostas por 24 e uma por 26 alunos. Eles tiveram a oportunidade de realizar a visitação às exposições, tendo o acompanhamento de suas professoras, que previamente haviam participado das oficinas de criação e experimentação.

A primeira oficina com os docentes foi ministrada por Chana de Moura: a artista trabalhou com técnicas mistas de ilustração e aquarela (Figuras 1 e 2). 


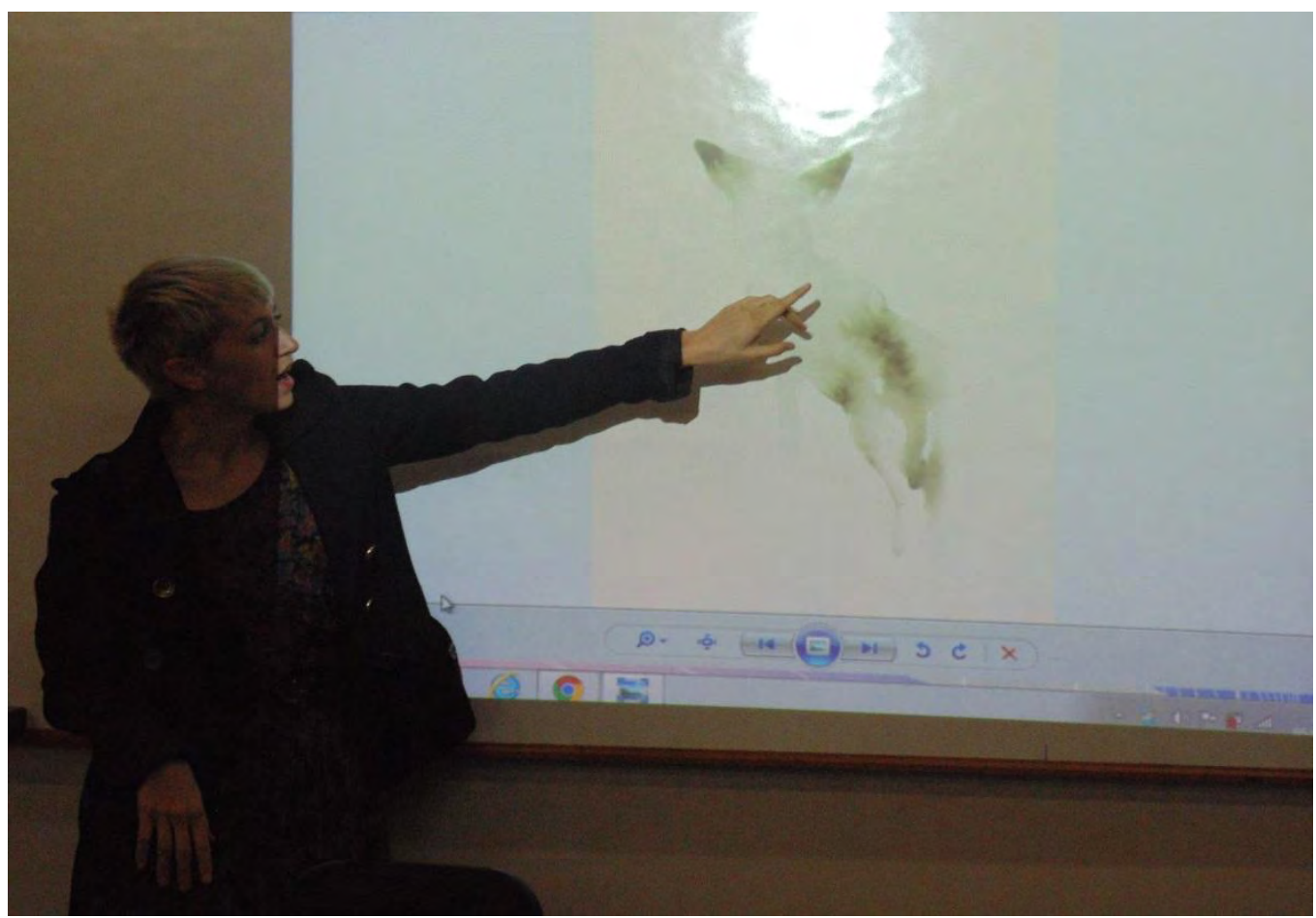

Figura 1: Apresentação de uma das técnicas utilizadas por Chana de Moura Fonte: Acervo do grupo de pesquisa CEM (2016)

A artista Chana de Moura, durante a manhã, compartilhou ideais sobre o processo criativo de seus desenhos, além dos materiais usados para a elaboração de suas obras; entre eles, estão os de maior importância: a água e a aquarela. Mas a artista também utiliza o café, o sal e o açúcar, que ajudam a mudar a textura da tinta no papel. Chana de Moura atua também em arte e educação, desenvolvendo trabalhos artísticos em diversas mídias, onde mistura técnicas de colagem, assemblage, fotografia, aquarela e outros materiais para "[...] tramar imagens e objetos que atuam como fluxos de pensamentos" (CHANA, 2017, texto digital).

Após escutarem sobre como utilizar a aquarela e as diversas possibilidades para criar com ela, as docentes acompanharam a ministrante para observar um pouco mais de sua obra na exposição "Cansada de ser ilha”, que estava ocorrendo no câmpus (conforme figura 2). Todas se mostraram muito interessadas e encantadas com os desenhos, as texturas e os poemas que também compõem a exposição de Chana de Moura. Aproveitaram o momento com a artista para fazes perguntas e discutir sobre seu trabalho. Durante a tarde, as professoras puderam experimentar todas as técnicas anteriormente citadas e ainda se aventurar por diversas outras que foram expostas durante a manhã. Este tornou-se, então, um momento de experimentação e de criação proposto para as docentes e participantes. 


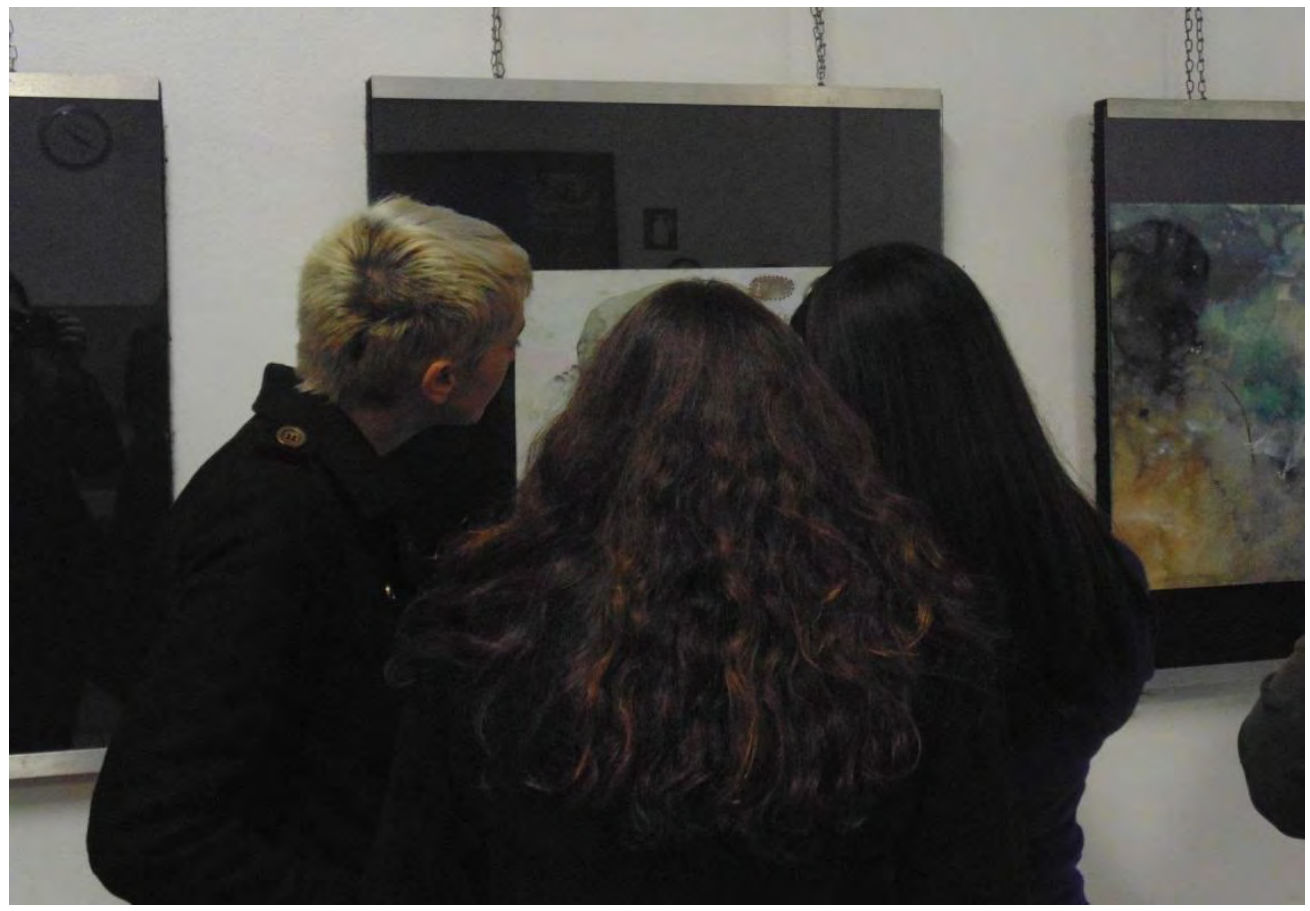

Figura 2: Momento de fruição das obras da artista Chana de Moura Fonte: Acervo do grupo de pesquisa CEM (2016)

Semanas depois, o momento de compartilhamento de ideias e produções foi de Augusto Bueno, que trabalhou com pintura tridimensional utilizando elementos da natureza, como galhos, folhas, sementes e pedras (Figuras 3 e 4).

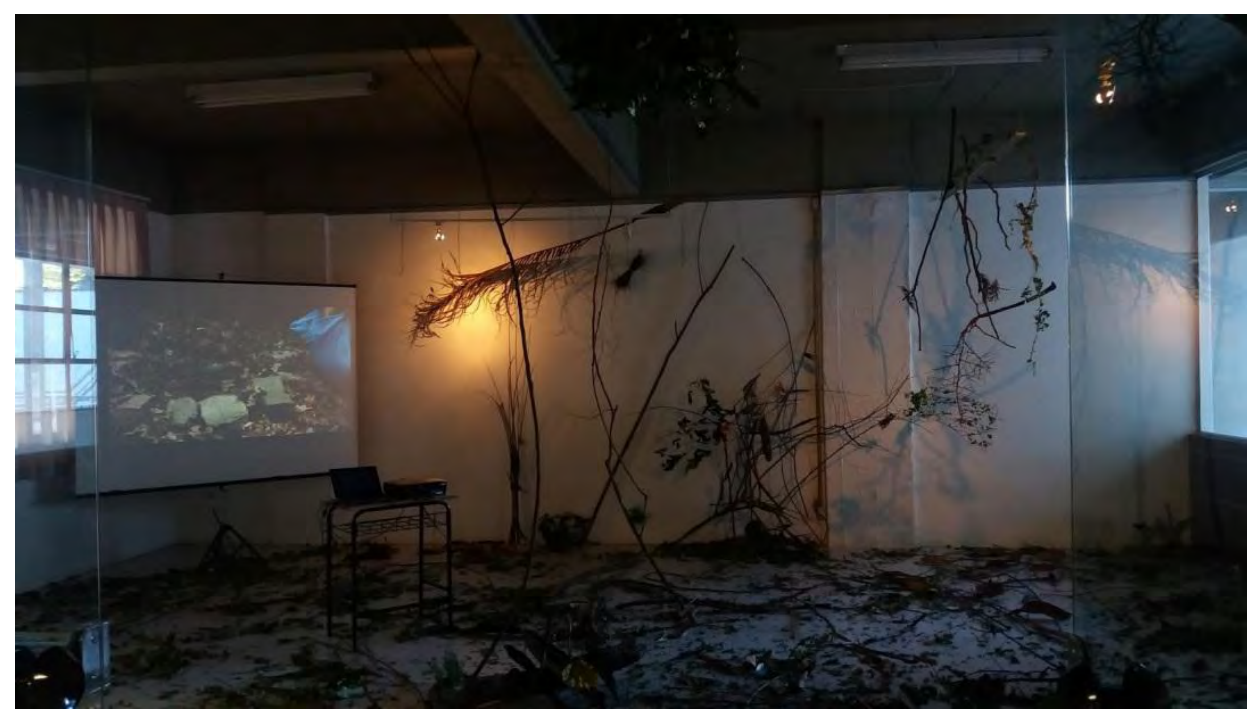

Figura 3: Intervenção feita pelo artista e pelas docentes

Fonte: Acervo do grupo de pesquisa CEM (2016) 
Um dos pontos marcantes dessa oficina para as professoras foi a caminhada por diversas partes do câmpus da universidade para recolher materiais da natureza, elas puderam conhecer de perto o processo que Augusto Bueno faz em Porto Alegre quando monta suas obras. Após recolherem folhas, galhos e flores, as docentes, junto com o artista, fizeram uma intervenção em uma sala destinada a exposições do Centro Universitário.

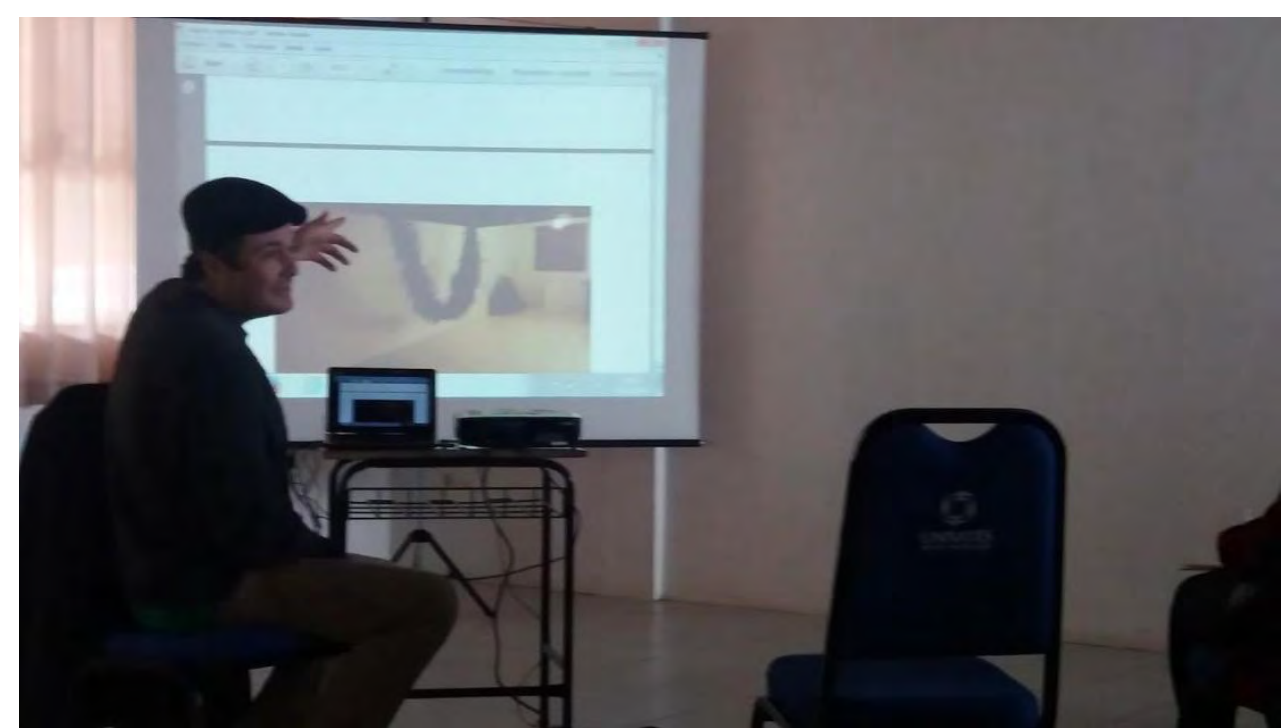

Figura 4: Artista mostrando uma parte do seu trabalho Fonte: Acervo do grupo de pesquisa CEM (2016)

Para finalizar o projeto, a artista Desiree de Azambuja Hirtenkauf também trabalhou com aquarela, partilhando um pouco de suas ideias e de seu gosto pelo bordado e trabalhos diretamente em tecidos (Figuras 5 e 6). A artista dedica-se ao desenho, à pintura e à escultura. 


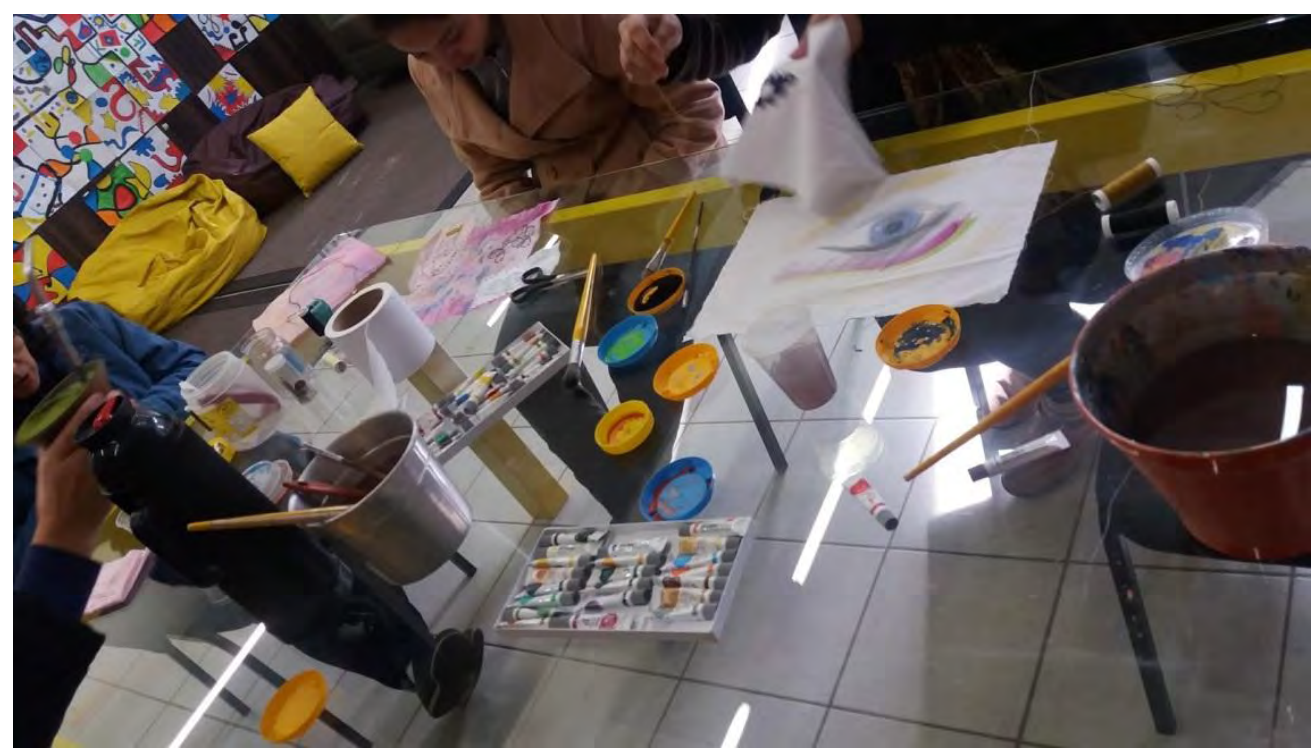

Figura 5: Nanquim e bordados na oficina da artista Desiree de Azambuja Hirtenkauf Fonte: Acervo do grupo de pesquisa CEM (2016)

Além de trabalhar a aquarela no papel, Desiree mostrou outras possibilidades para o uso da tinta, como por exemplo, o uso em tecidos com bordados. Este encontro remeteu muito à infância de algumas das professoras, que aprenderam a bordar com suas mães e avós. Após bordarem figuras e também frases, as docentes puderam experimentar a aquarela nos tecidos, seguindo as técnicas antes demonstradas. Essa oficina foi a que resultou em mais trabalhos, pois algumas das professoras que gostaram das experimentações bordaram e pintaram inúmeros tecidos, orgulhosas de suas produções. 

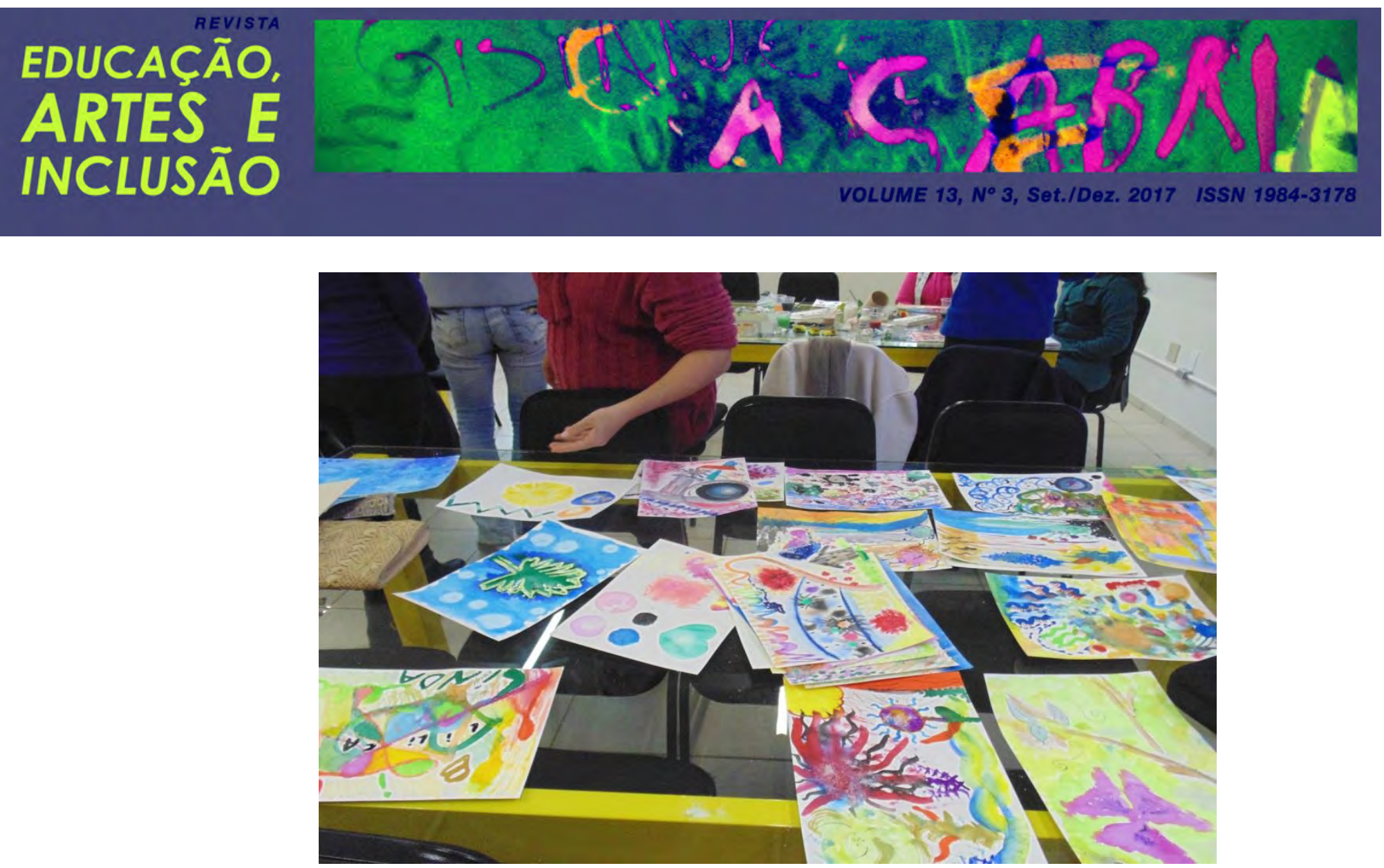

Figura 6: Produções com nanquim

Fonte: Acervo do grupo de pesquisa CEM (2016)

A figura 6 apresenta algumas produções realizadas pelas participantes das oficinas, momento em que as professoras que se permitiram explorar e aprender com a arte. Nas obras das participantes é possível perceber a diferença, a invenção, bem como uma multiplicidade de sentidos. As produções não são idênticas, nem buscam uma identidade, são "trans", atravessadas e atravessadoras, e estão em uma transversalidade em relação ao que lhes afetou e auxiliou em suas produções.

\section{AS DOCENTES ARTISTAS E SUAS PRÁTICAS}

Buscando, então, verificar o impacto do trabalho desenvolvido no fazer docente das professoras participantes, foram realizadas entrevistas semiestruturadas, compostas por quatro perguntas, entre os dias 15 e 21 de novembro de 2016. A partir dessas entrevistas, pudemos ter contato com oito dos docentes participantes do projeto. Por meio da fala de algumas professoras, pudemos perceber desconstruções de ideias já cristalizadas sobre formação docente, empoderamento sobre suas próprias práticas, relembranças de ideias e intervenções já esquecidas, principalmente no campo da arte e também surgiram novas propostas para construírem com seus alunos, na escola, no cotidiano de seu trabalho. Uma entrevistada 


\section{EDUCAÇÃO,

relata:

Acho que o projeto abriu para a gente uma nova visão de como trabalhar a arte de diferentes formas, a nossa turma explorou mais a técnica da aquarela, assistimos, ouvimos e representamos de diferentes formas [...] Mas enfim o mais gratificante foi poder tirar a forma que a gente aprendeu a trabalhar artes quando criança e reaprender a trabalhar isso de uma forma diferente com os pequenos, acho que isso foi mais gratificante (PROFESSORA 1).

Outra comenta:

Eu cheguei lá achando que eu não sabia fazer e eu desconstruí essa ideia e aprendi que sim, eu sou capaz [...] Eu tenho essa potência e não é a questão de fazer bonito mas o do próprio fazer e eu fiz e consegui (PROFESSORA 2).

Percebemos, a partir da fala das professoras, que sua participação nas oficinas as fez pensar sobre a aprendizagem, tanto de seus alunos como sua. Com isso destacamos que aprender não está relacionado somente com os alunos, mas envolve o próprio professor, que não aprende apenas para ensinar, mas para sua própria vida; ou seja, para compreender que ele também é capaz de produzir algo, de criar, aprender no sentido de uma formação estética da vida. Assim, os signos que os encontros de formação emitem "[...] podem ser interpretados e decifrados de diferentes maneiras e não mantêm com seu sentido uma relação idêntica, formando ao mesmo tempo uma unidade e uma pluralidade em diferentes mundos" (MUNHOZ et al., 2016, p. 10).

O aprender não está relacionado apenas às memórias já vividas, mas também por aquilo que nos "afecta e nos compõe" (MUNHOZ et al., 2016, p. 10), ou seja, estamos constantemente aprendendo e de algum modo aprendendo com o novo que chega a nós, seja uma palavra, um som, um cheiro. Conversando com as professoras ficou a forte impressão de que esses encontros com os artistas em seu processo de criação e a experimentação de técnicas aliada à reflexão sobre o processo produziu efeitos de sentido que potencializaram suas ações docentes. 
Para Ritcher (2003, p.114), “[...] o tempo utilizado em algo prazeroso, com um forte sentido simbólico e social permite além da satisfação estética outras socializações por meio do encontro". A partir de diversas respostas pudemos perceber que os três momentos marcaram cada uma de um modo diferente e o que chamou atenção foi que esses encontros tiveram um grande valor significativo, afetivo e estético. O projeto foi um trabalho coletivo, mas para cada uma teve um significado singular.

Um dos efeitos do projeto foi a desconstrução das dicotomias belo e feio, bom e mau, certo e errado, no que diz respeito à arte e docência. A partir da retomada desses conceitos e dessas desconstruções, puderam potencializar junto aos alunos a confiança no próprio fazer artístico. As falas das entrevistadas podem mostrar isso; quando perguntadas sobre o que mais as marcou no projeto, ressaltam:

Nos foi mostrado que às vezes as coisas que tu fazias e não valorizavas ou não se dava conta, são coisas simples, mas lindas do jeito delas [...] Então, em suma, o que marcou foram as técnicas e a confiança em si, e mostrou que a beleza está naquilo que é simples e já estava na tua cabeça há muito tempo, então houve esse resgate (PROFESSORA 3).

[...] muitas vezes tu faz uma coisa e tem vergonha, pensa que ficou feio e então não vai expor isso, sabe? E lá não tinha isso, tu começa naquilo pensando que é feio pra depois de pronto tu ver que ficou bonito, sabe? Então, eu acho que foi importante isso, a professora deu confiança pra gente, da gente também gostar do que fazemos, porque geralmente só achamos bonito o que o outro fez e às vezes temos vergonha e escondemos as coisas da gente, né? (PROFESSORA 4).

Além de pensar sobre os efeitos em suas produções, as professoras fizeram com que os alunos potencializassem a linguagem artística dentro da sala de aula; para isso, passaram segurança e incentivo em cada trabalho feito por eles. Como afirma a seguinte participante: 
Então lá ela deu liberdade pra termos confiança. Na prática da sala de aula quantas vezes a gente não faz isso, né? Muitas vezes o aluno tem vergonha de mostrar o seu trabalho então eu achei legal isso, ela nos deu confiança e essa mesma confiança que eu tive lá, eu também vou passar para o meu aluno, que o que ele faz também é bonito. (PROFESSORA 8)

Como ressalta Souza (2016, p. 203):

Compreende-se que o/a estudante deve ter a oportunidade de conhecer as diversas manifestações presentes no mundo, entretanto, deve também ter todo contato possível com o meio das artes que está relacionado às suas vivências locais. Busca-se, neste sentido, despertar no/a estudante a percepção de que a arte é o que o ser humano vive, constrói, cria e dá sentido [...]

A partir da fala das professoras o projeto trouxe à tona modos ainda vigentes de ver a arte dentro do campo educacional, mesmo em uma época de novas imagens e de novos arranjos estéticos, ainda surge a necessidade de explicação e definição do que seria a arte, como se sempre houvesse um sentido maior para aquilo que está sendo mostrado ou como se fosse um dever decifrar enigmas da criação artística para que seja mostrado depois aos alunos o que certa obra "quer dizer". Fischer (2014) relata:

Diferentemente da prática de buscar "o que o autor quis dizer", quando diante de obras de arte (poemas, romances, pinturas, desenhos, filmes) [...] talvez o que estejamos precisando seja exatamente o contrário: dispor-nos a enfrentar enigmas, entregando-nos a eles e aceitando que, muitas vezes, não há o que decifrar; há que se viver a beleza daquilo que "não nos diz tudo" tão claramente assim (FISCHER, 2014, p. 49).

Foi possível mostrar que cada participante, no momento, era autor de sua própria obra e cabia a cada um fazer intervenções que considerassem pertinentes satisfatórias, sem interferência ou alguém dizendo o que fazer, prescrevendo modos de "artistar". Mostrou-se que a arte tem diversos significados e não um específico para ser reproduzido. As técnicas foram apresentadas, porém cada uma utilizava do modo que quisesse, produzindo confiança 
na hora de criar, tal segurança acaba produzindo efeitos nos estudantes.

A experiência do projeto produziu efeitos na subjetividade de cada uma das participantes, pois a partir de sua criação entravam em contato consigo e com seu trabalho, pensando e recriando a sua prática docente. Em determinados momentos, pudemos perceber a sensibilidade de cada uma; às vezes, algumas das participantes se emocionavam, pois a intervenção que estava sendo feita remetia a momentos do início de sua caminhada como professora e também as levavam para memórias de suas infâncias. Essas experiências puderam ampliar a compreensão do seu papel como educadoras e também auxiliar no encontro com novos modos de docência. Modos de docência mais artistas que permeiam diferentes espaços e cenas do universo escolar, como ressalta Loponte (2017):

\begin{abstract}
Habitar uma escola é conviver com inúmeras e intermináveis tramas narrativas. Corredores, salas de aula, salas de professores, pátio, refeitórios, portaria, porta de entrada são cenários para professores, alunos e pais, que por vezes encontram nesses espaços acolhida de desejos, vontade e aprendizado mútuo ou um lugar em que nem sempre querem estar. Brigas, intrigas, frustrações, expectativas, (des)encontros, dramas, tragédias, alegrias, epifanias. Um grande espaço narrativo aberto a ser reinventado e repensado por meio de ações artísticas (LOPONTE, 2017, p.446).
\end{abstract}

\title{
5. CONSIDERAÇÕES FINAIS
}

Transvisões: aquarela, nanquim e pintura tridimensional constituiu-se em projeto que apostou misturar artistas e professores, aquarelas e bordados, ensaios e experimentações, propondo encontros entre arte e docência. Encontros que possibilitaram um pensar para além da docência através da arte: o prefixo trans atravessou os saberes e realidades, produzindo novas composições e arranjos.

Através da apreciação da exposição artística e da elaboração de propostas pedagógicas por meio da arte acredita-se que o referido projeto contribuiu no sentido de potencializar as práticas de criação dos docentes, provocando o fazer artístico e também contribuindo para o exercício da docência de professores da Educação Básica. Além de instigar e produzir ainda mais movimento nas práticas docentes, pode mobilizar reflexão e momentos propícios para a 
autoavaliação, para a revisão de conceitos cristalizados em relação à arte e, consequentemente, em relação à docência.

A partir do encontro com a arte, além de mudanças na sala de aula, ampliou-se o olhar sobre a formação docente de cada uma das participantes. Elas puderam perceber o quão imenso é o campo do conhecimento e das descobertas dentro da área da educação, não existindo um ponto final nessa busca por aprimoramento profissional e no processo de sua constituição como professoras.

Nesta busca, pode-se compreender que existem diversos caminhos e formas para colocar em prática seu trabalho, não se fechando em um só campo e uma só maneira, como destaca Loponte: "[...] o ato de educar é um ato de criação que envolve conhecimento e flexibilidade diante de alunos e situações pedagógicas" (LOPONTE, 2013, p. 40). Dessa forma, como nos mostraram os relatos das professoras, tornou-se possível a criação de outras práticas docentes junto aos estudantes.

Porém, percebe-se que, ainda com toda a experimentação e discussão sobre as dicotomias (belo e feio, por exemplo), elas continuam presentes nas falas das professoras, constituindo suas práticas. O que aponta a necessidade de seguir debatendo e pensando sobre estas questões.

Ao final, constata-se que o objetivo do projeto foi alcançado. O desejo de conhecer e de experimentar continua em movimento a partir das intervenções artísticas propostas nas oficinas. As docentes despertaram seu interesse para a arte e o direcionaram para seu trabalho, articulando o campo artístico e educacional. Elas tornaram-se amadoras, não no sentido de iniciantes, impotentes, mas sim no sentido de amar: pois para o amador não há “[...] ensaio, acerto ou erro, técnica ou ofício, ele exerce algo por gosto, por puro prazer" (MUNHOZ, 2016, p. 46). As docentes não tomaram a arte com o intuito de maestria ou de competição, mas sim com o desejo de uma formação e práticas pedagógicas "[...] marcadas pelas possibilidades de invenção contínua de si mesmo" (LOPONTE, 2013, p. 36) através da arte e de outros disparadores.

Incentivar a educação pela arte pode auxiliar a potencializar a capacidade de criação do professor junto a seus alunos. O projeto Transvisões explorou possibilidades dentro do 
universo das artes visuais, mas entendemos que a arte em geral, em suas mais diversas manifestações, amplia a vivência ético-estética dos sujeitos e os transforma. Assim, caminhase no sentido de cumprir o já referido compromisso da pesquisa em Educação: ao proporcionar esse espaço aos professores, o grupo de pesquisa Currículo, Espaço, Movimento (CEM) ampliou suas possibilidades de inserção junto às escolas e estreitou as relações junto aos docentes, produzindo efeitos em suas práticas. Dessa forma, reverberou igualmente na formação dos alunos, já que estes também puderam experienciar outras práticas a partir do exercício de formação de seus professores.

Ao final desta experiência, tanto da parte do grupo de pesquisa quanto das escolas participantes e das professoras envolvidas no projeto, permanece o desejo da construção de outras propostas que sigam buscando articulações entre arte e docência, possibilitando exercícios e ensaios que apostem na transversalidade constante dos saberes, do currículo, dos sujeitos.

\section{REFERÊNCIAS}

CABRAL, Ivone E. O compromisso social da pesquisa: implicações do pesquisador. In: LACERDA, Nilma; SIQUEIRA, Vera H. F de.; MIRANDA, Regina L. F de. Práticas pedagógicas na pósmodernidade. Rio de Janeiro: Editora UFRJ, 2012. p. 71-86.

CHANA de Moura. In: AURA ARTE - aproximações contemporâneas. Disponível em: < HYPERLINK

"https://www.aura.art.br/artistas/chana-demoura"https://www.aura.art.br/artistas/chana-de-moura>. Acesso em: 10 outubro 2017.

CORAZZA, Sandra. Uma vida de professora. Ijuí: Unijuí, 2005.

FALCÃO, Eliane B. M.; CERQUEIRA, Rui. Ativar ou desativar o interesse pelo outro: uma escolha para a universidade e para a ciência. In: LACERDA, Nilma; SIQUEIRA, Vera H. F de.; MIRANDA, Regina L. F de. Práticas pedagógicas na pós-modernidade. Rio de Janeiro: Editora UFRJ, 2012. p. 21-32.

FISCHER, R. M. B. Cinema e juventude: uma discussão sobre ética das imagens. Educação, v. 37, n. 1, p. 42-51, jan./abr. 2014.

GALLO, Sílvio. A orquídea e a vespa: transversalidade e currículo rizomático. In: GONSALVES, Elisa P.; CARVALHO, Maria Eulina P. PEREIRA, Maria Z. da C. Currículo e contemporaneidade: questões emergentes. Campinas, SP: Alínea, 2004. p. 37-50.

HATTGE, Morgana Domênica; HORN, Cláudia Inês; ALTHAUS, Henriqueta; FREITAS, Francine Nara de. Currículo, governamento e processos de subjetivação. In: MUNHOZ, Angélica Vier; 
COSTA, Cristiano Bedin da; OLHWEILER, Mariane Inês (Orgs). Currículo, Espaço, Movimento. Lajeado: Ed. Univates, 2016. p. 49 - 58.

HELGUERA, Pablo. Transpedagogia: a arte contemporânea e os veículos da educação. In: HOFF, Mônica. (Orgs.). Pedagogia no campo expandido. Porto Alegre: Fundação Bienal do Mercosul, 2011. p. 11-31.

LOPONTE, Luciana Gruppelli. Da arte docência e inquietações contemporâneas para a pesquisa em educação. Revista Teias, v. 14, n. 31, p. 34-45, 2013.

LOPONTE, Luciana Grupelli. Tudo isso que chamamos de formação estética: ressonâncias para a docência. Revista Brasileira Educação, v. 22, n. 69, p. 429-452, Junho de 2017. Disponível em: HYPERLINK "http://www.scielo.br/scielo.php?script=sci arttext\&pid=S141324782017000200429\&lng=en\&nrm=iso\&tlng=pt"http://www.scielo.br/scielo.php?script=sci_arttext\& pid=S1413-24782017000200429\&lng=en\&nrm=iso\&tlng=pt. Acesso em: 15 mai. 2017.

MUNHOZ, Angélica Vier; HATTGE, Morgana Domênica. Algumas notas sobre espaços e movimentos do currículo. Revista Espaço do Currículo, v. 8, n. 3,p. 316-322, set/dez de 2016. Disponível em: HYPERLINK "http://periodicos.ufpb.br/index.php/rec/article/view/rec.2015.v8n3.317322"http://periodicos.ufpb.br/i ndex.php/rec/article/view/rec.2015.v8n3.317322. Acesso em: 14 mai. 2017.

MUNHOZ, Angélica Vier et al. Aprender no encontro com o mestre. In: MUNHOZ, Angélica Vier; COSTA, Cristiano Bedin da; OLHWEILER, Mariane Inês (Orgs). Currículo, Espaço, Movimento. Lajeado: Ed. Univates, 2016. p. 7-18.

RITCHER, Ivone Mendes. Interculturalidade e Estética do Cotidiano no ensino das Artes Visuais. Campinas: Mercado das Letras, 2003.

SOUZA, Netto. Das tripas à arte - processos de ensino em arte-educação a partir das obras de Lenice Weis. Revista Educação, Artes e Inclusão, v. 12, n. 3, 2016. p. 202-225.

Recebido em 26 de maio de 2017 Aprovado em 25 de outubro de 2017 